\title{
Crescimento e fotossíntese de plantas de pinhão-manso cultivadas em diferentes condições de luminosidade
}

\author{
Anderson A. Schock ${ }^{1}$, Aline Ramm², Emanuela G. Martinazzo ${ }^{3}$, Diolina M. Silva ${ }^{4} \&$ Marcos A. Bacarin ${ }^{5}$ \\ ${ }^{1}$ Laboratório de Metabolismo Vegetal, UFPel, Pelotas, RS. E-mail: verdepracaramba@yahoo.com.br \\ ${ }^{2}$ Laboratório de Metabolismo Vegetal, UFPel, Pelotas, RS. E-mail: alineramm@yahoo.com.br \\ ${ }^{3}$ Laboratório de Metabolismo Vegetal, UFPel, Pelotas, RS. E-mail: emartinazzo@gmail.com \\ ${ }^{4}$ CCHN/DCB/UFES, Vitória, ES. E-mail: diu@terra.com.br \\ ${ }^{5}$ Laboratório de Metabolismo Vegetal, UFPel, Pelotas, RS. E-mail: bacarin@ufpel.edu.br (Autor correspondente)
}

Palavras-chave:

Jatropha curcas L.

fluorescência da clorofila a

desenvolvimento

\begin{abstract}
R E S U M O
O pinhão-manso (Jatropha curcas L.) tem-se destacado, no cenário do biodiesel, em função da porcentagem de óleo contido nas sementes e de sua capacidade adaptativa. No País, a cultura do pinhão-manso tem, como proposta, o desenvolvimento agronômico, razão pela qual o uso consorciado pode ser importante aos pequenos produtores. Este trabalho teve como objetivo avaliar algumas características fenológicas de pinhão-manso cultivado em dois regimes de luminosidade (pleno sol e sombrite 50\%) relacionando com a sazonalidade climática e se utilizando de parâmetros da fluorescência da clorofila e de trocas gasosas. As plantas apresentaram crescimento vegetativo com padrão sazonal, com pico de crescimento no início de março, quando iniciou a senescência foliar. Alguns parâmetros da fluorescência transiente da clorofila analisados pelo Teste JIP, apresentaram relação com as flutuações ambientais. $\mathrm{O} \mathrm{PI}_{\mathrm{ABS}}$ e o $\mathrm{PI}_{\text {total }}$ demonstraram que as plantas do tratamento sombreado foram sensíveis à redução de luminosidade. A taxa assimilatória líquida e a eficiência de carboxilação reduziram ao longo do experimento acompanhando a queda da radiação solar; já as plantas de pinhão-manso respondem negativamente a essas condições de sombreamento.
\end{abstract}

Key words:

Jatropha curcas L.

chlorophyll a fluorescence

development

\section{Growth and photosynthesis of Physic nut grown under different light conditions}

\begin{abstract}
A B S T R A C T
Jatropha curcas L. has been prominent in the scenario of biodiesel due to the percentage of oil contained in the seeds and its adaptive capacity. The cultivation of J. curcas in the country has as proposal the agronomic development and its consortium may be important for small producers. This study aimed to characterize the phenological behavior of J. curcas grown under different light conditions, full sun and $50 \%$ shade, relating them to the climatic seasonality, comparing their development with chlorophyll a fluorescence and gas exchange. Plants showed vegetative growth with seasonal pattern, with growth peak at the beginning of March, when the leaf senescence began. The analysis of the kinetic of the transient fluorescence of chlorophyll presented a relationship between certain parameters of the test JIP and the environmental fluctuations. The $\mathrm{PI}_{\mathrm{ABS}}$ and the $\mathrm{PI}_{\text {total }}$ demonstrated that in the shaded treatment plants were sensitive to luminosity reduction. The liquid assimilation rate and the carboxylation efficiency decreased throughout the experiment, accompanying the decline of the solar radiation. J. curcas plants respond negatively to these shaded conditions.
\end{abstract}

\section{INTRODUÇÃo}

A preocupação com o meio ambiente e a previsão da extinção dos combustíveis fósseis, foram o viés para o início dos investimentos em pesquisas com diferentes formas de produção de energia, sobretudo os biocombustíveis. Atualmente, espécies oleaginosas são estudadas em grande número para o desenvolvimento de estratégias de cultivo e beneficiamento de seus produtos objetivando otimizar a relação custo/beneficio na produção de óleos vegetais para biodiesel. Neste contexto, o pinhão-manso (Jatropha curcas L.) tem sido considerado uma das oleaginosas mais promissoras para substituir o diesel de petróleo tendo em vista a quantidade e a qualidade do óleo produzido na semente (Sachs, 2010) além de ser uma espécie perene e não possuir restrições edafoclimáticas para seu desenvolvimento.

Provavelmente originária da América Central, plantas de pinhão-manso são encontradas desde o nível do mar até 1200 $\mathrm{m}$ de altitude. Apesar de ser uma espécie adaptada a regiões de 
clima mais quente cuja temperatura média varia entre 18,0 e 28,5 ${ }^{\circ} \mathrm{C}$ também pode ser encontrada em regiões de clima tropical, subtropical e temperado; contudo, sua ocorrência é menor nas regiões de temperaturas mais baixas (Heller, 1996), porém estudos de caracterização fotossintética de pinhão-manso em ambientes de baixa temperatura associados ou não a diferentes luminosidades, são escassos na literatura.

Considerando que a disponibilidade de água e nutrientes são fatores mais facilmente controláveis em processos agronômicos, as condições de luminosidade se tornam de suma importância no desenvolvimento, crescimento e produção dos vegetais. Assim, o manejo da luminosidade é de importância relevante para o crescimento vegetal. Por outro lado, a alta radiação pode causar destruição foto-oxidativa do aparato fotossintético, em especial do fotossistema II (FSII), refletindo na diminuição transitória ou até permanente da eficiência quântica da fotossíntese (Cabrera, 2002). Além disto, a exposição direta ao sol pode elevar grandemente a temperatura das folhas intensificando a taxa respiratória, o que induziria ao fechamento dos estômatos reduzindo a fixação de carbono e causando aumento no consumo de fotoassimilados (Kozlowski et al., 1991).

Sob condições de sombreamento a temperatura das folhas favorece a abertura estomática e a fixação de carbono conferindo controle do status hídrico da planta, otimizando a atividade fotossintética em função da turgescência celular (Reis, 1991).

A dependência da luz nos processos fisiológicos das plantas se reflete na sua manutenção homeostática. Em função disso, a maioria das plantas desenvolve capacidade para aclimatar-se às variações de temperatura e luminosidade (Searle et al., 2011), regulando a condutância estomática (Aasamaa \& Sõber, 2011) e ajustando o aparato fotossintético para absorção adequada, transferência e utilização da energia eletromagnética disponível (Gonçalves et al., 2010).

O trabalho teve como objetivo avaliar parâmetros de crescimento e características fotossintéticas de plantas de Jatropha curcas cultivadas em dois níveis de luminosidade.

\section{Material e Métodos}

O experimento foi conduzido na Universidade Federal de Pelotas, Campus Capão do Leão, Município de Capão do Leão, RS, utilizando-se sementes de Jatropha curcas L. (pinhão-manso). As sementes foram provenientes de produtor estabelecido na região de Janaúba, MG, originadas em plantas matrizes de qualidade. Cinco sementes foram colocadas para germinar em vasos de polietileno preto, furados, cada um com capacidade de $15 \mathrm{~kg}$ contendo solo oriundo de região de mata, como substrato, o qual foi previamente adubado com NPK (711-9). A semeadura foi realizada em 21/10/2010. A irrigação de todos os vasos foi realizada duas vezes por semana.

Os vasos foram dispostos em espaçamento de $1,0 \times 1,0 \mathrm{~m}$, sob duas condições de luminosidade: a) pleno sol, denominado tratamento sol, e b) sombreado, denominado tratamento sombrite, obtido por meio de uma estrutura de 2,0 m, fechada por todos os lados com sombrite de $50 \%$ de redução da luminosidade (verificada com a utilização de sensor quântico, modelo Quantum Sensor-Red, Hansatech Instruments Ltd, King's Lynn, Northfolk, UK).

Avaliaram-se a porcentagem de germinação e o índice de velocidade de emergência (IVE) empregando-se a fórmula proposta por Popinigis (1977), sendo IVE $=\left(\mathrm{E}_{1} / \mathrm{N}_{1}\right)+\left(\mathrm{E}_{2} / \mathrm{N}_{2}\right)+$ $\ldots+\left(\mathrm{E}_{\mathrm{n}} / \mathrm{N}_{\mathrm{n}}\right)$, em que: IVE - índice de velocidade de emergência; $\mathrm{E}$ - número de plântulas normais computadas nas contagens; $\mathrm{N}$ - número de dias da semeadura à $1^{\mathrm{a}}, 2^{\mathrm{a}}$... enésima avaliação. Para tanto, a contagem do número de plantas emergidas iniciou-se aos nove dias após a semeadura (DAS), sendo realizada diariamente até sua estabilização. Nos dias 4/11/2011 e 10/11/2011 foram realizadas medidas da temperatura do solo a cinco centímetros de profundidade com uso de termômetro digital (Digital Termometer, HandHeld, Westerm ${ }^{\circ}$ ). As leituras da temperatura do solo foram realizadas às 9:00, 12:00 e 15:00 h, sendo calculados os valores médios entre os três períodos. No final da contagem da emergência o desbaste foi realizado deixando-se somente uma planta por vaso; ainda durante todo o período experimental dados agrometeorológicos foram extraídos de boletins emitidos pela Estação Agroclimatológica de Pelotas (Capão do Leão-RS $-31^{\circ} 52^{\prime} 00^{\prime \prime} \mathrm{S}-52^{\circ} 21^{\prime} 24^{\prime \prime}$ W. GRW).

Parâmetros de crescimento (altura do caule, número de folha e diâmetro do caule) foram medidos aos 41, 63, 99, 162, 192 e 216 DAS; nessas mesmas datas foram mensuradas a fluorescência transiente da clorofila $a$ e as trocas gasosas utilizando-se a segunda folha superior totalmente expandida.

A fluorescência transiente OJIP da clorofila $a$ foi determinada com o uso de fluorômetro portátil (Modelo Handy PEA, Hansatech Instruments, King's Lynn, Norfolk, UK). As folhas, não destacadas, foram previamente adaptadas ao escuro por 60 minutos para oxidação completa do sistema fotossintético de transporte de elétrons. A emissão de fluorescência foi induzida em uma área de $4 \mathrm{~mm}$ de diâmetro pela exposição da amostra a um pulso saturante de luz vermelha (pico $650 \mathrm{~nm}$ ) e intensidade $3.000 \mu \mathrm{mol} \mathrm{m} \mathrm{m}^{-2} \mathrm{~s}^{-1}$. As intensidades de fluorescência foram medidas entre $50 \mu$ s e $1 \mathrm{~s}$, donde: $50 \mu \mathrm{s}\left(\mathrm{F}_{50 \text { us }}\right.$ - fluorescência inicial), $100 \mu \mathrm{s}\left(\mathrm{F}_{100 \mu \mathrm{s}}\right), 300 \mu \mathrm{s}\left(\mathrm{F}_{300 \mu \mathrm{s}}\right), 2 \mathrm{~ms}\left(\mathrm{~F}_{2 \mathrm{~ms}}\right.$ - ponto $\left.\mathrm{J}\right), 30$ $\mathrm{ms}\left(\mathrm{F}_{30 \mathrm{~ms}}\right.$ - ponto $\left.\mathrm{I}\right)$ e $\mathrm{F}_{\mathrm{m}}$ (fluorescência máxima) foram utilizadas para calcular os parâmetros estabelecidos pelo Teste JIP (Strasser \& Strasser, 1995) utilizando-se o software Biolyzer.

As trocas gasosas foram medidas nas mesmas folhas utilizadas para determinação da fluorescência OJIP, com uso de um analisador portátil a infra-vermelho de $\mathrm{CO}_{2}$ (Modelo LI-6400XT LI-COR, Inc., Lincoln, NE, USA). As medidas foram realizadas entre as 10:00 e 11:00 h. Foram utilizadas concentração de $380 \mathrm{~mol} \mathrm{~mol}^{-1}$ de $\mathrm{CO}_{2}$ no interior da câmara e densidade de fluxo de fótons fotossinteticamente ativos de $1.500 \mu \mathrm{mol} \mathrm{m}^{-2} \mathrm{~s}^{-1}$, empregando-se a fonte luminosa LI-COR 6400-02, acoplada a câmara de medida. As variáveis estimadas segundo o modelo de Caemmerer \& Farquhar (1981), foram: taxa assimilatória líquida de $\mathrm{CO}_{2}(\mathrm{~A})$; condutância estomática $\left(\mathrm{g}_{\mathrm{S}}\right)$; taxa transpiratória (E) e concentração intercelular de 
$\mathrm{CO}_{2}\left(\mathrm{C}_{\mathrm{i}}\right)$; a partir das medidas da $\mathrm{A}$ e $\mathrm{C}_{\mathrm{i}}$ calculou-se a eficiência aparente de carboxilação $\left(\mathrm{A} / \mathrm{C}_{\mathrm{i}}\right)$. O experimento foi conduzido em delineamento experimental inteiramente casualizado, com 15 repetições por tratamentos. Os dados foram submetidos a análise de variância e quando o teste $\mathrm{F}$ foi significativo as médias foram comparadas pelo Teste de Tukey $(\mathrm{p}<0,05)$ sendo as comparações realizadas em cada coleta.

\section{Resultados e Discussão}

Durante o experimento as condições climáticas se mantiveram dentro dos padrões normais para a região com picos de temperatura, em especial na primeira quinzena do mês de novembro; no restante, assim continuaram cartesianamente em forma de parábola sendo que as temperaturas médias mais elevadas ocorreram durante os meses de janeiro e março, ou seja, entre os 60 e 140 dias do início do experimento (Figura 1).

As sementes mantidas no tratamento sol iniciaram a emergência aos 9 DAS enquanto as mantidas sob sombrite apresentaram atraso médio de cinco dias. A percentagem de sementes emergidas e o IVE foram superiores no tratamento sol. Tal fato pode estar associado à temperatura média do solo mais elevada nos vasos mantidos a pleno sol (média $34^{\circ} \mathrm{C}$ ) em comparação com os vasos mantidos sombreados (média $26^{\circ} \mathrm{C}$ ). Para a germinação a temperatura adequada é de suma importância pois age na velocidade de absorção
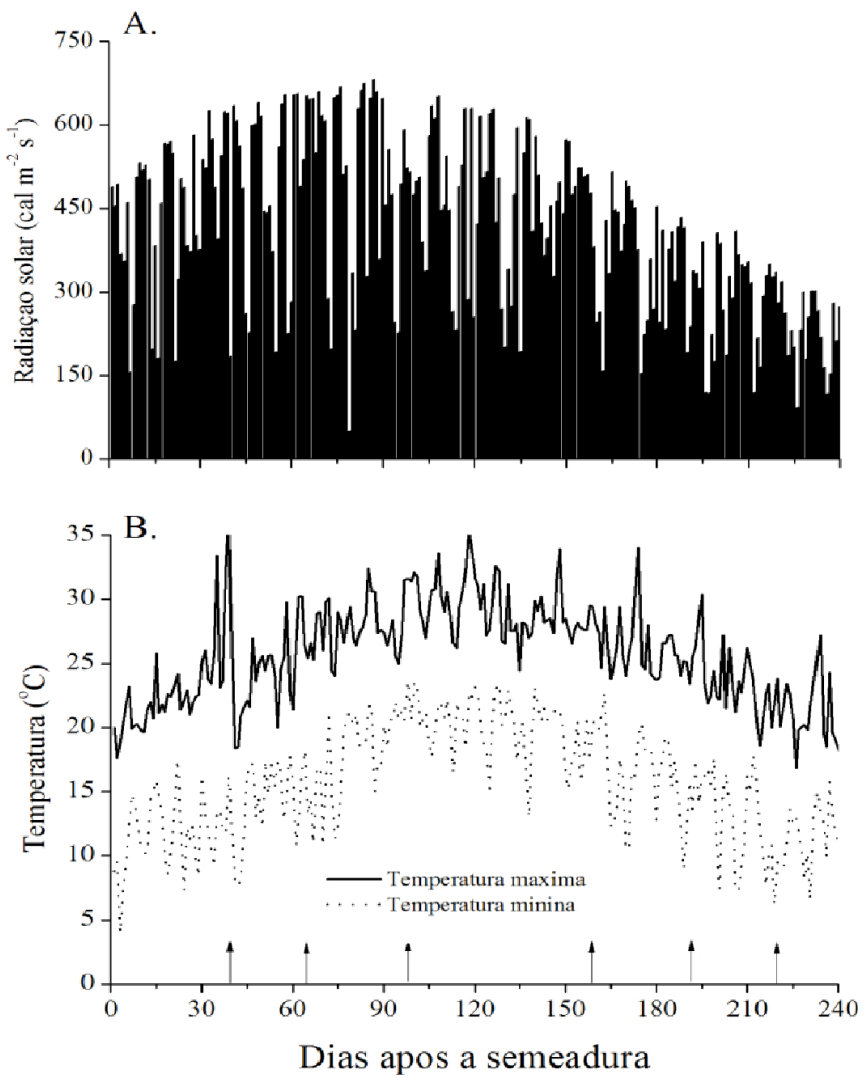

Figura 1. Radiação solar (A) e temperaturas máxima e mínima (B) medidas durante o período de 21/10/2010 a 31/05/2011. As setas indicam as datas de coleta de água e nas inúmeras reações bioquímicas (Bewley \& Black, 1994).

A altura das plantas não foi influenciada pelos tratamentos sendo que as plantas cresceram até aproximadamente 90100 DAS (Figura 2A). Quanto ao diâmetro do caule, plantas do tratamento pleno sol se mostraram significativamente mais espessas (Figura 2B), durante todo o período do experimento.
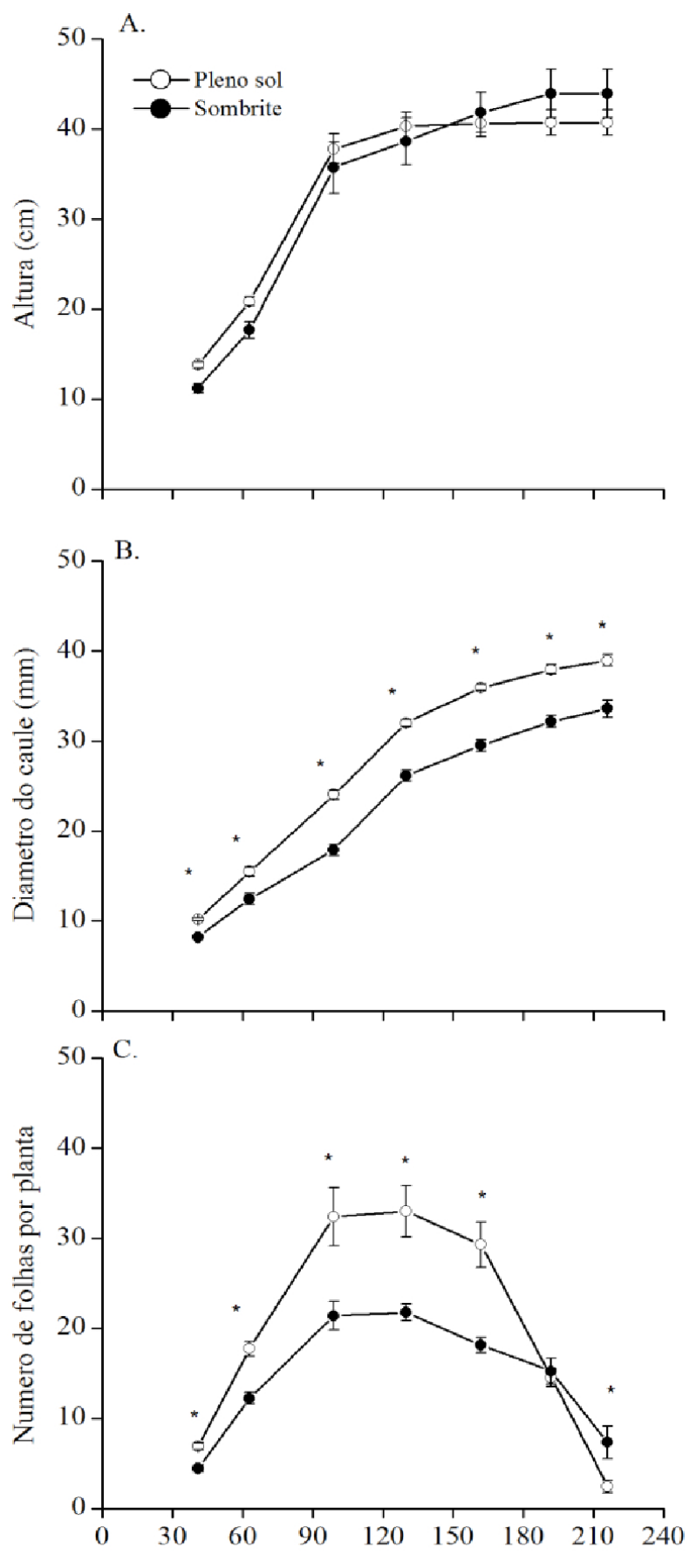

Dias apos semeadura

* Indica diferença estatística entre os diferentes regimes de luminosidade para cada data de coleta. Barra indica erro padrão da média. $\mathrm{N}=15$

Figura 2. Altura (A), diâmetro do caule (B) e número de folhas por planta $(C)$ do pinhão-manso cultivado sob pleno sol (--০--) e sombrite (--•--) 
O número de folhas foi crescente até os 99 DAS com posterior redução e completa ausência das mesmas ao final do experimento (Figura 2C), sendo que esta queda ocorreu no período de redução das temperaturas e da radiação. Pode-se observar que as plantas mantidas em pleno sol apresentaram, praticamente durante todo o experimento, maior número de folhas atingindo aproximadamente 1,5 vez o número de folhas das plantas sombreadas entre 90 e 120 DAS. O padrão no número de folha foi típico de plantas caducifólias, sendo que a senescência acompanhou a redução na temperatura e radiação solar (Figura 1). As folhas são os principais órgãos fotossintetizantes denominadas fonte a partir do seu primeiro terço de expansão total e consideradas órgãos de maior plasticidade frente às flutuações ambientais (Huang et al., 2011). Plantas mantidas sob maior incidência luminosa tendem a apresentar maior número de folhas (Dousseau et al., 2007), fato que corrobora com o presente trabalho.

Em relação aos parâmetros de fluorescência da clorofila pode-se destacar que nas plantas cultivadas sob sombrite foi observada tendência de maiores valores médios de fluxos de absorção (ABS/RC) e de captura por centro de reação $\left(\mathrm{TR}_{0} / \mathrm{RC}\right)$ até os 99 DAS, com posterior redução até os 162 DAS (Figura $3 A-B)$. Os valores médios do rendimento quântico de redução dos aceptores finais de elétrons do fotossistema I (FS I) por fóton absorvido $\left(\mathrm{RE}_{0} / \mathrm{RC}\right)$ (Figura 3D) foram ligeiramente superiores nas plantas cultivadas em pleno sol apresentando queda ao final do experimento, coincidentes com a redução da temperatura mínima e no número de folhas.

A similaridade nos padrões de tendência entre $A B S / \mathrm{RC}_{0}$ e $\mathrm{TR}_{0} / \mathrm{RC}$ indica que não houve limitação no processo de absorção e transferência de energia. Todavia, as plantas mantidas sombreadas apresentaram valores médios mais elevados para esses fluxos. Neste sentido e sob redução de luminosidade, o estado de excitação das moléculas do complexo antena que canaliza a transferência de energia até os centros de reação, foi capaz de reduzir a feoftina iniciando a cadeia de oxirredução da fase fotoquímica da fotossíntese, sem qualquer limitação. Isto se deve ao fato de que plantas crescidas em ambientes sombreados além de possuírem mais grana por cloroplastos também apresentam maior quantidade de clorofila por centro de reação (Fahl et al., 1994). Tal processo pode ser verificado no fluxo de transporte de elétrons por centro de reação ( $\mathrm{ET}_{0} /$ $\mathrm{RC}$ ), o qual apresentou valores ligeiramente mais elevados para as plantas do tratamento sombrite.

Os valores superiores do fluxo de redução dos aceptores finais de elétrons do FSI por centro de reação $\left(\mathrm{RE}_{0} / \mathrm{RC}\right)$ nas plantas cultivadas a pleno sol, foram tangenciados por resposta às variações climáticas, principalmente da temperatura mínima.

$\mathrm{O}$ rendimento quântico fotoquímico primário máximo $\left(\mathrm{TR}_{0} / \mathrm{ABS}=\varphi_{\mathrm{P}_{\mathrm{o}}}\right)$ não apresentou diferenças entre os tratamentos (Figura 4A). Por outro lado, o rendimento quântico de transporte de elétrons $\left(\mathrm{ET}_{0} / \mathrm{ABS}=\varphi_{\mathrm{E}_{\mathrm{o}}}\right)($ Figura $4 \mathrm{~B})$ apresentou comportamento parabólico durante o experimento. $\mathrm{O}$ rendimento quântico estimado pela redução dos aceptores finais
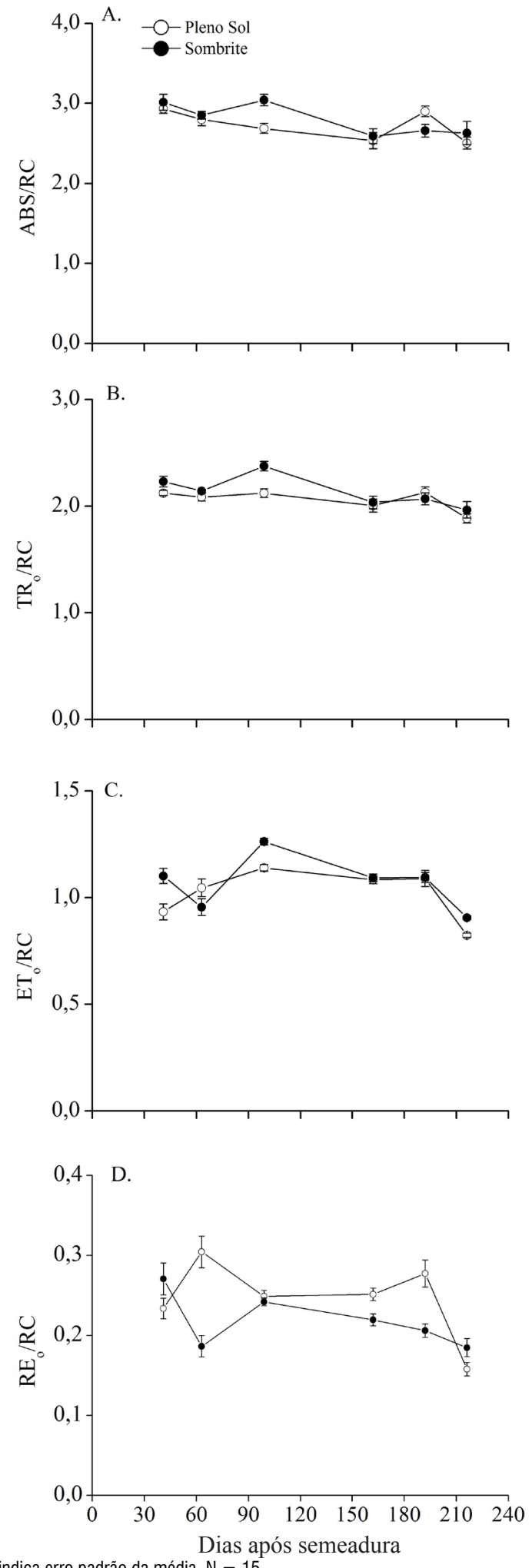

* Barra indica erro padrão da média. $\mathrm{N}=15$

Figura 3. Fluxo específico de absorção por centro de reação $(A B S / R C)(A)$, fluxo específico de captura por centro de reação $\left(T_{0} / R C\right)(B)$, fluxo específico de transporte de elétrons por centro de reação ( $\mathrm{ET}_{0} /$ RC) (C) e fluxo específico de redução do aceptor de elétrons do fotossistema I por centro de reação $\left(\mathrm{RE}_{0} /\right.$ RC) (D) de plantas de pinhão- manso cultivadas sob pleno sol (--o--) e sombrite (--•--) 
de elétrons do FSI por fóton absorvido $\left(\varphi_{\mathrm{Ro}}\right)$ foi, a exceção do início (41 DAS) e final do experimento (216 DAS), maior nas plantas cultivadas em pleno sol indicando maior redução dos aceptores finais do FSI (Figura 4C).

Os rendimentos quânticos, em especial $\varphi_{\mathrm{Eo}}$ e $\varphi_{\mathrm{Ro}}$, refletem o comportamento da probabilidade com que um éxciton capturado no centro de reação pode mover um elétron de $\mathrm{Q}_{\mathrm{A}}^{-}$ para o intersistema de aceptores de elétrons $\left(\Psi_{\mathrm{EO}_{0}}\right)$ e a eficiência com que um elétron pode mover-se do intersistema de aceptores de elétrons reduzidos para o aceptor final de elétrons do FSI $\left(\delta_{\mathrm{Ro}}\right)$ (Figura $4 \mathrm{D}-\mathrm{E}$ ). Este trabalho demonstra que as plantas cultivadas em menor densidade de fluxo de fótons podem desenvolver mecanismos para aproveitamento mais eficiente da radiação e que plantas em alta densidade luminosa tem a possibilidade de reduzir a foto-oxidação pela elevação da atividade do FSI direcionando os elétrons para outras rotas, como reação de Mehler, por exemplo, evitando a formação de espécies reativas de oxigênio (Nishiyamaet al., 2011) o que poderia prejudicar este fluxo de elétrons.

Os índices de performance $\mathrm{PI}_{\mathrm{ABS}}$ e $\mathrm{PI}_{\text {total }}$, (Figura 5) apresentaram valores médios superiores nas plantas do tratamento sol, sendo crescentes com o aumento de folhas e decrescentes com a diminuição das mesmas atingindo seu máximo entre 99 e 162 DAS. Os índices de performance são os mais representativos do comportamento do fluxo energético na cadeia de transporte de elétrons da fotossíntese (Yusuf et al., 2010). Assim, alterações nesses parâmetros são excelentes indicadores da atividade fotossintética ou mesmo do efeito de estresse em que as plantas estão ou ao qual foram submetidas, o que pode danificar, direta ou indiretamente, o aparato fotossintético. Desta forma, a redução do fluxo de energia luminosa incidente sobre as plantas de pinhão-manso reduziu a velocidade no fluxo de elétrons propiciando atraso para que as plantas atingissem os máximos valores de $\mathrm{PI}_{\mathrm{ABS}}$ e $\mathrm{PI}_{\text {total }}$. Tal fato demonstra o grau de adaptabilidade da espécie frente a essas condições e corrobora com Huang et al. (2011) para Athyrium pachyphlebium.

Os parâmetros de trocas gasosas apresentaram redução ao longo do experimento (Figura 6), acompanhando a variação da temperatura. No que concerne à diferença de luminosidade, pode-se destacar que as plantas cultivadas em pleno sol apresentaram maiores valores de taxa assimilatória líquida e eficiência de carboxilação até 120 DAS (Figura 6A e D) embora a taxa transpiratória foi maior nas plantas cultivadas em sombrite entre 60 e 150 DAS.

As reduções em parâmetros de trocas gasosas ocorreram em virtude da baixa disponibilidade de irradiância e da redução de temperatura influenciadas pela sazonalidade, reduzindo as taxas fotossintéticas e, em consequência, o ganho de carbono (Valladares \& Pearcy, 1998), o que justifica o fato desses parâmetros serem mais elevados no tratamento sol.

A condutância estomática varia em função da variação de temperatura, ou seja, maiores valores de condutância estomática ocorrem quando a radiação solar é máxima,
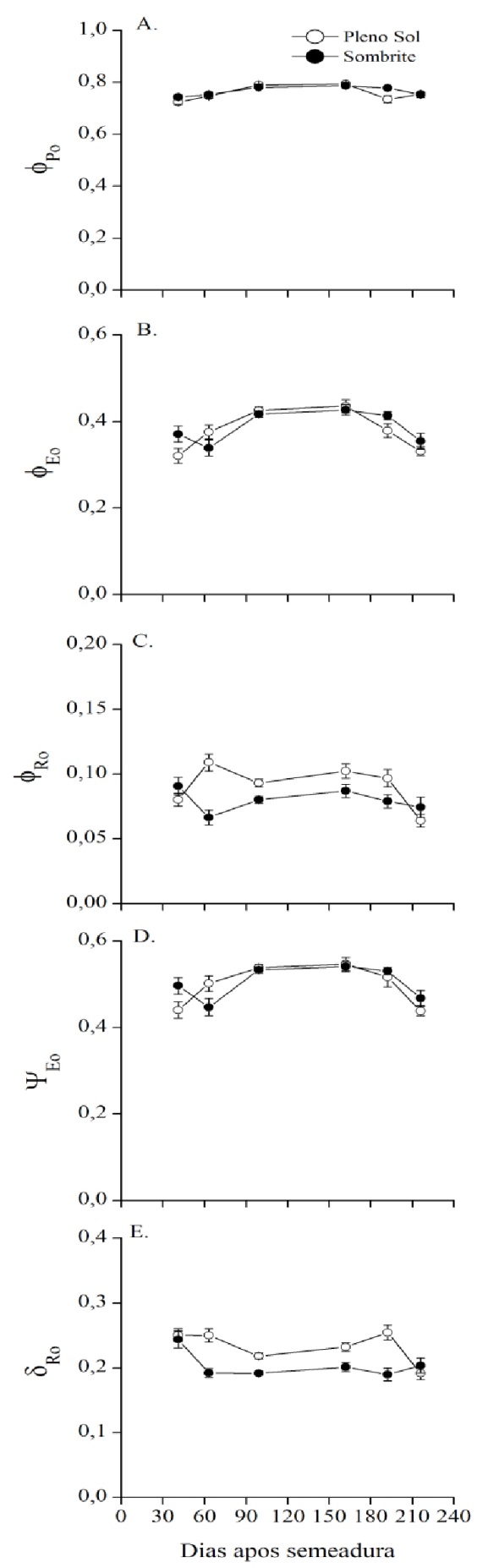

* Barra indica erro padrão da média. $\mathrm{N}=15$

Figura 4. Rendimento quântico fotoquímico máximo $\left(\varphi_{\mathrm{Po}_{0}}\right)(\mathrm{A})$, rendimento quântico de transporte de elétrons $\left(\varphi_{\mathrm{EO}}\right)(B)$, rendimento quântico de redução dos aceptores finais de elétrons do fotossistema I por fóton absorvido $\left(\varphi_{R o}\right)(C)$, probabilidade (no tempo 0 ) de que um exciton capturado em mover um elétron na cadeia de transporte de elétrons após $\mathrm{Q}_{\mathrm{A}-}\left(\Psi_{\mathrm{Eo}}\right)$ (D) e eficiência com que um elétron pode mover dos aceptores de elétrons do intersistema reduzidos para os aceptores finais do fotossistema I $\left(\delta_{R o}\right)(E)$ de plantas de pinhão-manso cultivadas sob pleno sol (--०--) e sombrite (--•--) 


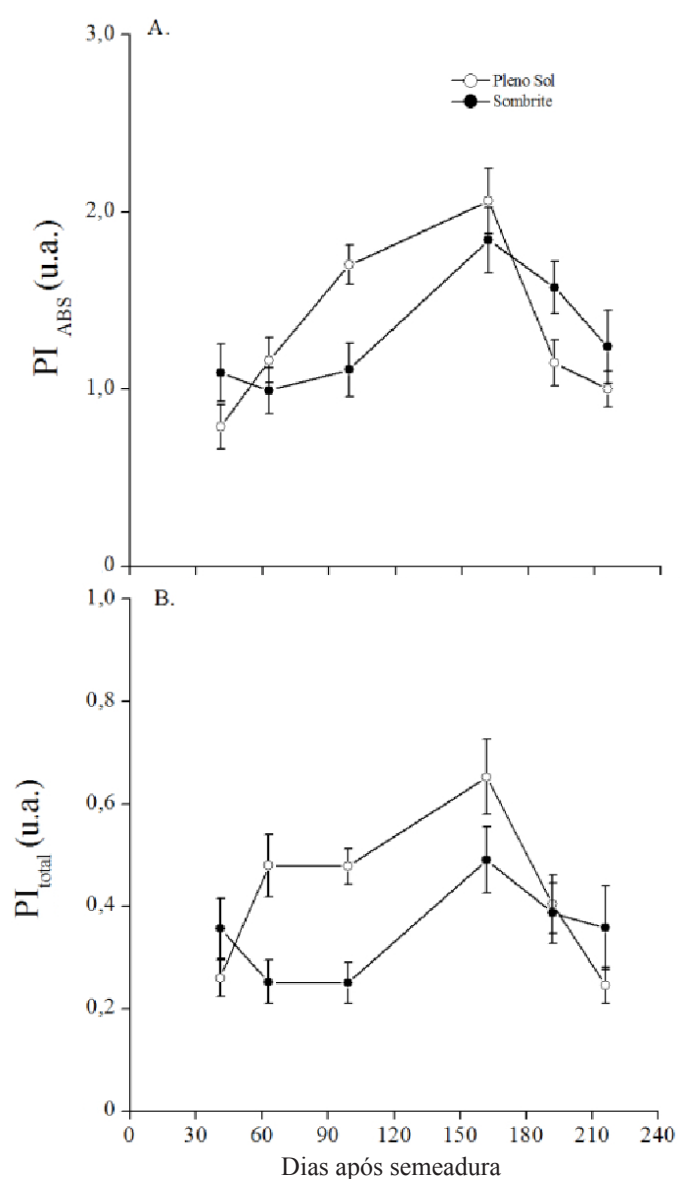

Figura 5. Índice de performance fotossintético (A) $\left(\mathrm{PI}_{\mathrm{ABS}}\right)$ e índice de performance fotossintético total (B) $\left(\mathrm{PI}_{\text {total }}\right)$ de plantas de pinhão-manso cultivadas sob pleno sol (--o--) e sombrite (--•--)

até que o potencial hídrico da folha reduza, induzindo o fechamento dos estômatos (Ferreira et al., 1999). Porém Costa \& Marenco (2007) relatam que a intensidade luminosa é um dos principais fatores responsáveis pela condutância estomática refletindo nas taxas assimilatória líquida e na eficiência de carboxilação.

Os valores transpiratórios mais elevados no tratamento sombrite podem estar associados à menor variação da umidade relativa do ar, característica comum a ambientes mantidos nessas condições (Souza et al., 2011). Por outro lado, maior transpiração pode aumentar a espessura da camada limítrofe de vapor de água existente na interface folha ar, aumentando a resistência à entrada de $\mathrm{CO}_{2}$ através dos estômatos, influenciando na relação entre taxa assimilatória líquida e eficiência de carboxilação, parâmetros que foram menores no tratamento sombrite.

A elevação da temperatura devida à maior radiação incidida sobre as folhas, aumenta a diferença de pressão de vapor entre o ar e a folha facilitando a transpiração e elevando a taxa transpiratória (Luttge, 1997). Este fato fez com que a taxa transpiratória também acompanhasse a curva de temperatura e luminosidade inferida pela sazonalidade reduzindo, concomitantemente, as variáveis ambientais mencionadas.
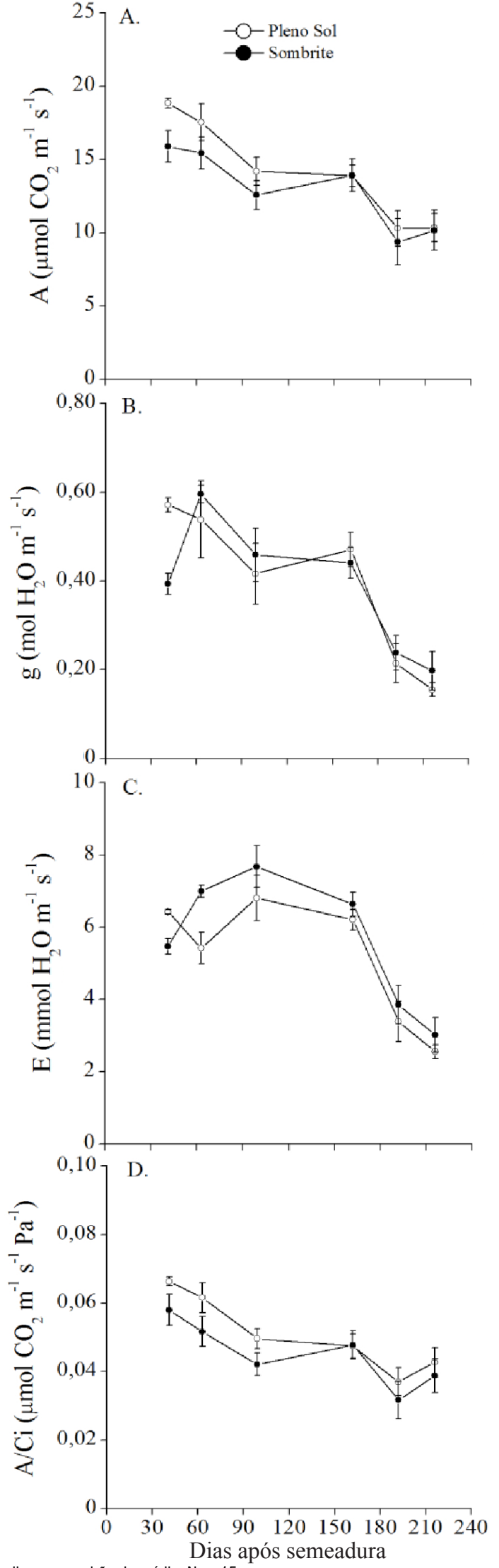

* Barra indica erro padrão da média. $\mathrm{N}=15$

Figura 6. Taxa assimilatória líquida (A), condutância estomática (C), taxa de transpiração (E) e eficiência de carboxilação (G) de plantas de pinhão-manso cultivadas sob pleno sol (--০--) e sombrite (--•--) 


\section{Conclusões}

1. A condição de sombreamento diminui a percentagem e velocidade de emergência das plântulas de pinhão-manso.

2. A altura das plantas não é afetada pela diferença de luminosidade porém plantas cultivadas em luminosidade reduzida apresentam caules menos espessos.

3. O número de folhas é maior nas plantas cultivadas em pleno sol.

4. Os índices de performance $\mathrm{PI}_{\mathrm{ABS}}$ e $\mathrm{PI}_{\text {total }}$, são superiores nas plantas cultivadas em pleno sol.

5. As plantas cultivadas em pleno sol apresentam maiores taxas assimilatórias líquidas e eficiência de carboxilação.

\section{Agradecimentos}

Ao CNPq, CAPES, MCT e à FINEP, pelo suporte financeiro e auxílio com bolsas, e ao Dr. Reto Strasser da Universidade de Genebra, pela utilização do software Biolyzer.

\section{Literatura Citada}

Aasamaa, K.; Sõber, A. Stomatal sensitivities to changes in leaf water potential, air humidity, $\mathrm{CO}_{2}$ concentration and light intensity, and the effect of abscisic acid on the sensitivities in six temperate deciduous tree species. Environmental and Experimental Botany, v.71, p.72-78, 2011.

Bewley, J. D.; Black, M. Seeds: Physiology of development and germination. New York: Plenum Press, 1994. 445p.

Cabrera, H. M. Respuestas ecofisiológicas de plantas em ecosistemas de zonas con clima mediterráneo y ambientes de alta montaña. Revista Chilena de Historia Natural, v.7, p.625-637, 2002.

Caemmerer, S. von; Farquhar, G. D. Some relationships between the biochemistry of photosynthesis and the gas ex-change of leaves. Planta, v.153, p.376-387, 1981.

Costa, G. F.; Marenco R. A. Fotossíntese, condutância estomática e potencial hídrico foliar em árvores jovens de andiroba (Carapa guianensis). Acta Amazonica, v.37, p.229-234, 2007.

Dousseau, S.; Alvarenga A. A.; Santos, M. de O.; Arantes, L. de O. Influência de diferentes condições de sombreamento sobre o crescimento de Tapirira guianensi Alb. Revista Brasileira de Biociências, v.5, p.477-479, 2007.

Fahl, J. I.; Carelli, M. L. C.; Vega J.; Magalhães, E. A. C., Nitrogen and irradiance levels affecting net photosynthesis and growth of young coffee plants (Coffea Arabica L.). Journal of Horticultural Science, v.69, p.161-169, 1994.

Ferreira, C. A. G.; da Vide, A. C.; Carvalho, L. R. Relações hídricas em mudas de Eucalyptus citriodora Hook., em tubetes, aclimatadas por tratamentos hídricos. Cerne, v.5, p.95-104, 1999.

Gonçalves, J. F. C.; Silva, C. E. ; Guimarães, D. G.; Bernardes, R. S. Análise dos Transientes da Fluorescência da Clorofila $a$ de Plantas Jovens de Carapa guianensis e de Dipteryx odorata submetidas a dois ambientes de luz. Acta Amazônica, v.40, p.89-98, 2010.
Heller, J. Physic nut (Jatropha curcas L.): Promoting the conservation and use of underutilized and neglected crops. Rome: Institute of Plant Genetics and Crop Plant Research, Gatersleben/ International Plant Genetic Resources Institute, 1996. 66p.

Huang, D.; Wu L.; Chen J. R.; Dong L. Morphological plasticity, photosynthesis and chlorophyll fluorescence of Athyrium pachyphlebium at different shade levels. Photosynthetica, v.49, p.611-618, 2011.

Kozlowski, T. T.; Kramer, P. J.; Pallardy, S. G. The physiological ecology of woody plants. San Diego: Academic Press, 1991. $657 \mathrm{p}$.

Luttge, U. Interaction of stress factors and the midday depression in plants with C3: photosynthesis. Physiological Ecology of Tropical Plants, v.35, p.122-124, 1997.

Nishiyama Y.; Suleyman I. A.; Murata N. Protein synthesis is the primary target of reactive oxygen species in the photoinhibition of photosystem II. Physiologia Plantarum, v.142, p.35-46, 2011.

Popinigis, F. Fisiologia de sementes. Brasília: AGIPLAN, 1977. 289p.

Reis, G. G. Crescimento e ponto de compensação lumínico em mudas de espécie florestais nativas submetidas a diferentes níveis de sombreamento. Revista Árvore, v.18, p.103-111, 1991.

Sachs, G. Commodity prices and volatility: Old answers to new questions, Global Economics Paper, n.194, p.1-17, 2010.

Searle, S. Y.; Thomas, S.; Griffin, K. L.; Horton, T.; Kornfeld, A.; Yakir, D.; Hurry, V.; Turnbull, M. H. Leaf respiration and alternative oxidase in field-grown alpine grasses respond to natural changes in temperature and light. New Phytologist, v.189, p.1027-1039, 2011.

Souza, C. D. de; Fernandes, D. P.; Barroso, M. R.; Portes, T. A. Transpiração de espécies típicas do cerrado medida por transpirômetro de equilíbrio e porômetro. Cerne, v.17, p.509-515, 2011.

Strasser, B. J.; Strasser, R. J. Measuring fast fluorescence transient to address environmental questions: The JIP-test. In: Mathis, P. Photosynthesis: From light to biosphere. Dordrecht: Kluwer Academic Publisher, 1995. p.977-980.

Valladares, F.; Pearcy, R. W. The funcional ecology of shoot architecture in sun and shade plants of Heteromeles arbutifolia M. Roem., a Californian chaparral shrub. Oecologia, v.114, p.1-10, 1998.

Yusuf, M. A.; Kumar, D.; Rajwanshi, R.; Strasser, R. J.; Tsimilli-Michael, M.; Govindjee, Sarin, N. B. Overexpression of $y$-tocopherol methyl transferase gene in transgenic Brassica juncea plants alleviates abiotic stress: Physiological and chlorophyll a fluorescence measurements. Biochimica et Biophysica Acta, v.1797, p.1428-1438, 2010. 